\title{
ZEOLITE BASED MICROCONCENTRATORS FOR VOLATILE ORGANIC COMPOUNDS SENSING AT TRACE-LEVEL: FABRICATION AND PERFORMANCE
}

\author{
Fernando Almazán ${ }^{1}$, Ismael Pellejero ${ }^{1}$, Alberto Morales ${ }^{1}$, Miguel A. \\ Urbiztondo $^{1,2}$, Javier Sesé ${ }^{1}$, M. Pilar Pina ${ }^{1,3^{*}}$, Jesús Santamaría ${ }^{1,3}$ \\ ${ }^{1}$ Nanoscience Institute of Aragón (INA); University of Zaragoza; Edif. I+D+i, Campus \\ Rio Ebro, c/Mariano Esquillor s/n, 50018 Zaragoza, Spain. \\ ${ }^{2}$ Centro Universitario de la Defensa, Academia General Militar, 50090 Zaragoza, \\ Spain \\ ${ }^{3}$ Networking Research Center on Bioengineering, Biomaterials and Nanomedicine, \\ CIBER-BBN, 50018 Zaragoza, Spain \\ *Corresponding Author: tel. +34 976 761155, fax. +34 976762142 e- \\ mail: mapina@unizar.es
}

\begin{abstract}
A novel 6-step microfabrication process is proposed in this work to prepare microfluidic devices with integrated zeolite layers. In particular, microfabricated preconcentrators designed for volatile organic compounds (VOC) sensing applications are fully described. The main novelty of this work is the integration of the pure siliceous MFI type zeolite (silicalite-1) polycrystalline layer, i.e $4.0 \pm 0.5 \mu \mathrm{m}$ thick, as active phase, within the microfabrication process just before the anodic bonding step. Following this new procedure, Si microdevices with an excellent distribution of the adsorbent material, integrated resistive heaters and Pyrex caps have been obtained. Firstly, the microconcentrator performance has been assessed by means of the normal hexane breakthrough curves as a function of sampling and desorption flowrates, temperature and micropreconcentrator design. In a step further, the best preconcentrator device has been tested in combination with downstream $\mathrm{Si}$ based microcantilevers deployed as VOC detectors. Thus, a preliminar evaluation of the improvement on detection sensitivity by silicalite- 1 based microconcentrators is presented.
\end{abstract}

Keywords: MEMS concentrator, intergrowth zeolite layer, Silicalite-1, nhexane, microcantilever, VOC detection. 


\section{Introduction}

Miniaturized integrated systems called lab-on-a-chip microdevices have been found great acceptance in many fields such as bioassays, chemical reactions, separation, sensing platforms [1-5], to name a few. Progress in this area has been preceded by the improvement in the techniques of micromachining, microlithography, and microfluidics, which have allowed the miniaturization of many devices currently incorporated in our modern life. Miniaturization allows the integration of several processes into a single portable device; and furthermore, it introduces additional advantages compared to macroscopic systems [6-7], such as providing new functionalities, better interaction between components, process mass intensity, power consumption reduction or lower manufacturing cost.

One of the most important advantages of analytical lab-on-a-chip devices is the low sample consumption, being necessary in many applications a sample pre-concentration or controlled storage of it. More specifically, this work pursues the development of a zeolite based microconcentrator incorporated at the front end of a microcantilever based sensing unit for detection at ppm level of volatile organic compounds from minute quantities of vapors (few microliters). Concentrating target analyte in a stage prior to the detection unit, substantially improves detector response in terms of sensitivity and selectivity. The key advantages of MEMS $\mu$-preconcentrators include sharper desorption pulse, low energy consumption and ease of integration with microsensors. However, the main technical difficulties rely not only on the properties of the active phase, i.e. adsorption capacity, selectivity and desorption efficiency-reversibility; but also on the fluidic control of the sample, i.e. minimum sample volume, flow rate for analyte collection, desorption bandwidth. In this field, extensive efforts have been focused on the design, fabrication, integration of different microsensors (temperature and pressure), careful adjustment of the operating conditions and performance assessment for the specific application for which the device was conceived [8-19]. Important advances have been carried out at the Virginia Tech MEMS Lab [11-15] and Integrated Environmental Microsystems (University of Michigan) [16-19]; reporting great progress on microconcentrators with integrated heaters and sensors oriented to portable gas chromatography for vapor trace detection (explosive markers, hazardous pollutants, biomarkers of exposure/disease in breath...)

The core of any adsorption-based technology is an adsorbent. Selection of the active material compromises efficiency and selectivity of whole microdevice, and even fabrication process [20-21]. Active materials most widely used in MEMS microconcentrators are engineering polymers like Tenax ${ }^{\circledR}$ polymer (2,6-diphenyl-p-phenylene oxide) [22-23] or activated porous carbon [24-25]. Those materials exhibit adequate sorption properties and are commonly deposited by pumping through the fluidic channel. In this context, nanoporous materials like microporous zeolites have not been fully explored as active coatings on $\mu$-preconcentrators.

Particularly, zeolites constitute a family of highly interesting technological materials, on account of their framework structure, with pores of subnanometric size, and their remarkable properties in catalysis and adsorption. The possibility of hosting different ions, atoms, molecules and clusters in the zeolite structures has opened up numerous opportunities as nanomaterials with advanced properties. Accordingly, our research pursues the exploration of new applications at the micro-scale, such as microreactors, microsensors, smart coatings, drug delivery, etc... [26-27]. Given the interesting properties of zeolite coatings, significant efforts has been devoted to combine the experience gathered in growing zeolite films and the fabrication methods used in the electronic industry [28] to prepare zeolite based microdevices on Si wafers following standard microfabrication schemes. Thus, zeolite only microcantilevers and zeolite micromembranes on customized silicon nitride microsieves have been successfully accomplished [29-30] and demonstrated for VOC detection and $\mathrm{CO}_{2}$ separation, respectively.

In this work, we present an innovative fabrication way to integrate zeolitic continuous layers as active phase on the microfluidic channel. According to different reviews [9-10], the conventional way to introduce the active phase, mainly polymers, is post-fabrication, once the microfluidic device has 
been sealed and chip by chip. The solution of the sorbent precursor is commonly drawn through the fluidic channel using a pump [20,25,31-34]. Scarce reproducibility on coverage and uniformity and low throughput are the main drawbacks related to this approach. On the other hand, ink-jet printing is becoming popular [22, 35-36]. Unlike previously, our strategy involves the synthesis and patterning of the active microporous phase onto the microfluidic channel. Thus, sorbent loadings and uniform coverage of the exposed surface are greatly improved; and, enhanced concentration and separation capabilities towards the target analyte are expected. In addition, thanks to the incorporation of the stationary phase - loading step within the microfabrication scheme, the reproducibility is notably increased and the process is greatly simplified.

The selected zeolite as active phase for our microconcentrator is Silicalite-1, an MFI-type zeolite with $\mathrm{Si} / \mathrm{Al}$ ratio $\infty$. MFI-type zeolites have been widely investigated in numerous adsorption and diffusion studies on volatile organic compounds (VOCs), and particularly on hexane isomers [37-38]. The channel topology of MFI type zeolites consists of intersecting straight (elliptical with diameters equal to $0.52 \times 0.58 \mathrm{~nm}$ ) and sinusoidal channels (circular with a diameter of $0.54 \mathrm{~nm}$ ). Molecules hosted in the narrow pores of MFI exhibit strong interactions with the pore walls, leading to pronounced differences in adsorption depending on size, polarity, and shape. Henry adsorption constant values depend on zeolite composition due to adsorbate-adsorbent interactions. At $20^{\circ}-27^{\circ} \mathrm{C}$, the reported n-hexane $(0.43 \mathrm{~nm}$ as kinetic diameter) sorption capacity of the silicalite- 1 zeolite is around $1.35 \mathrm{mmol} / \mathrm{g}$ [37-38]. Operating at lower temperatures increases both the equilibrium and kinetic selectivity of n-hexane versus the di-branched hexane isomers, allowing selective sorption processes [38]. Furthermore, all the zeolite adsorption capacities remain unchanged after several adsorption-desorption (at $350^{\circ} \mathrm{C}$ ) cycles [37]. Recently, metal-organic frameworks (MOFs) have attracted increased attention due to their ultrahigh specific area. At $25^{\circ}-27^{\circ} \mathrm{C}$, the reported n-hexane sorption capacity of MIL 101 is around $9.5 \mathrm{mmol} / \mathrm{g}$ [39]. However, the limited thermal stability of most MOFs precludes their use on devices exposed to uniform thermal heating with short time constants.

The quantitative analysis of mixtures of VOCs at the low concentrations is required for demanding applications such as monitoring of ambient or indoor air pollutants [10, 40-41], explosive markers for homeland security [20, 33, 42-44], breath analysis for biomedical diagnostics [14, 45-46] or for forensic biomarkers identification [47]. Thus, the herein attempted combination of Silicalite-1 based microconcentrators and microcantilevers has been validated on n-hexane detection at ppm level. In this work, n-hexane has been chosen as probe molecule due to its hydrophobic nature (high affinity towards de silicalite- 1 framework) and its molecular diameter $(0.52 \mathrm{~nm})$. In addition, n-hexane is commonly used as solvent and degreaser; and its occupational safety exposure limit (threshold limit value-time-weighted average) is $20 \mathrm{ppm}$. Furthermore, the herein obtained results are also of particular interest for other indoor - outdoor applications involving volatile organic compounds (alkanes, alkenes, ketones, aromatics, aldehydes) with similar features.

\section{Microfabrication process}

Basically, the microconcentrator fabrication scheme involves 6 basic steps (A to F) comprising photolithography, wet etching, synthesis of polycrystalline zeolite layer, anodic bonding processes. An additional step (F) is included to integrate a metallic heater on the back side of the chip. The experimental procedure is schematically depicted in Figure 1. This scheme can be followed not only for microconcentrators, but for any other microfluidic devices with integrated silicalite-1 on channels.

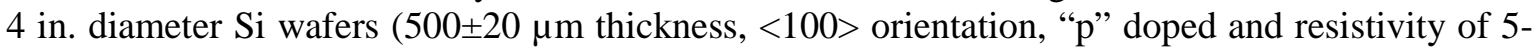
$10 \Omega \cdot \mathrm{cm}$ ) supplied by Sil'Tronix Silicon Technologies were used. Firstly, the photolithography process was carried out on the top side of the wafer to define the microconcentrator design (step A) by using a specific negative-working photosensitive resist ProTEK ${ }^{\circledR}$ PSB (Brewer Science). The main feature of ProTEK ${ }^{\circledR}$ is its non-degradable character under alkaline etching conditions [48]. This 
property reveals essential for the herein proposed fabrication scheme due to the photosensitive coating has to support strong alkaline conditions during $\mathrm{KOH}$ etching (step B) and zeolite synthesis (step C). Bulk silicon etching (step B) is carried out with $\mathrm{KOH}$ (Panreac) $40 \% \mathrm{w} / \mathrm{v}$ at $80^{\circ} \mathrm{C}$ for $1 \mathrm{~h}$ in order to define channel depth $(\sim 100 \mu \mathrm{m})$. During this process, a special 4 in. PEEK holder (Advanced Micromachining Tools GmbH - AMMT) is used to protect back side and edge of the wafer from the alkaline solution. Once microchannels are fabricated and before ProTEK ${ }^{\circledR}$ PSB resist removal, synthesis of Silicalite-1 type zeolite onto whole wafer (step C) is carried out as following the same procedure described in previous works [28]. According to SEM observations, the zeolite layer is $4.0 \pm$ $0.5 \mu \mathrm{m}$ thick. Free volume and exposed surface of the microfluidic channels are calculated taking into account anisotropic behavior of Si etching. This phenomena leads the formation of trapezoidal columns, provoking an increase of the zeolite loading on pillared designs. The zeolite loading for the studied microconcentrators (see Table 1) has been estimated from the layer thickness, the designed exposed area and the channel depth, considering $2 \mathrm{~kg} / \mathrm{m}^{3}$ as the density of the polycrystalline zeolite layer [29]. .

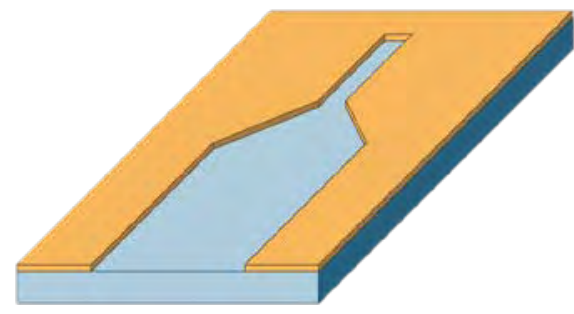

A. ProTEK PSB photolithography process

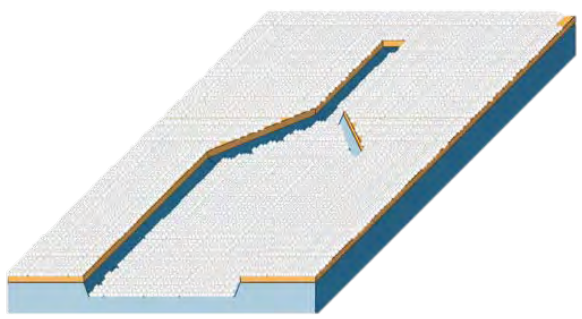

C. Hydrothermal synthesis of Silicalite-1 layer

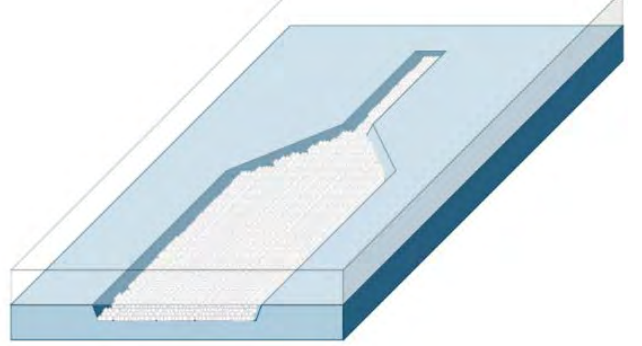

E. Sealing by Anodic bonding

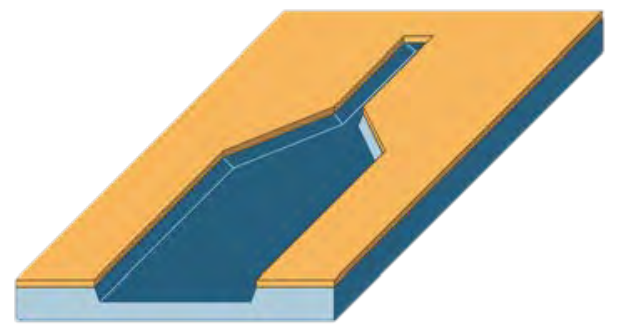

B. Channel definition by $\mathrm{KOH}$ etching

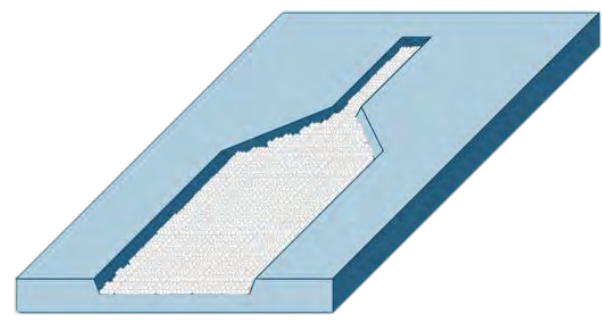

D. ProTEK removal, lift-off process

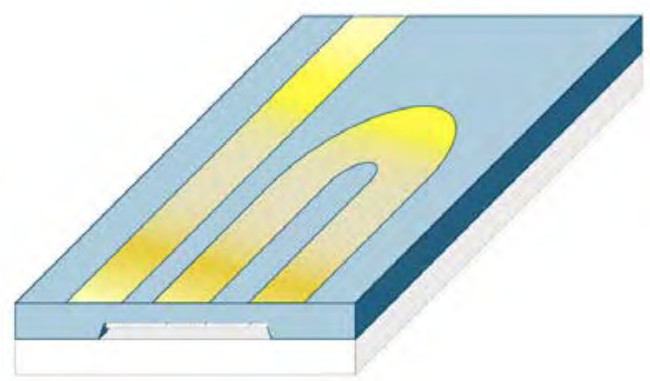

F. Photolithography, Au deposition, lift-off process for heater definition on the back side

Figure 1. General microfabrication scheme for microconcentrator with integrated zeolite polycrystalline layer. 
Figure 2 shows the photolithographic masks for the microconcentrators studied in this work. Masks were designed by using Clewin $5 \AA$ software and were printed in high grade acetate film by Micro Lithography Services Ltd. Four different designs are fabricated in every 4 in. wafer. Design B, $\mathrm{C}$ and $\mathrm{D}$ will become a micro-pillared structure once they are fabricated; meanwhile, design A will be a free- microfluidic channel. In general, pillars within microfluidic channels are aimed at improving the gas and the stationary phase distribution; whereas, at the same time provide interfacial contact for the anodic bonding (step E). Computer modelling in COMSOL Multiphysics was simultaneously performed to ensure acceptable pressure drop values along the microfluidic devices. The theoretical $\Delta \mathrm{P}$ values are below $1 \mathrm{mbar}$ for $10 \mathrm{~mL} / \mathrm{min}$. On the contrary, the experimental $\Delta \mathrm{P}$ values are circa 30 mbar. These discrepancies are mainly attributed to the inlet and outlet ports where the sound-blasting residues are accumulated.

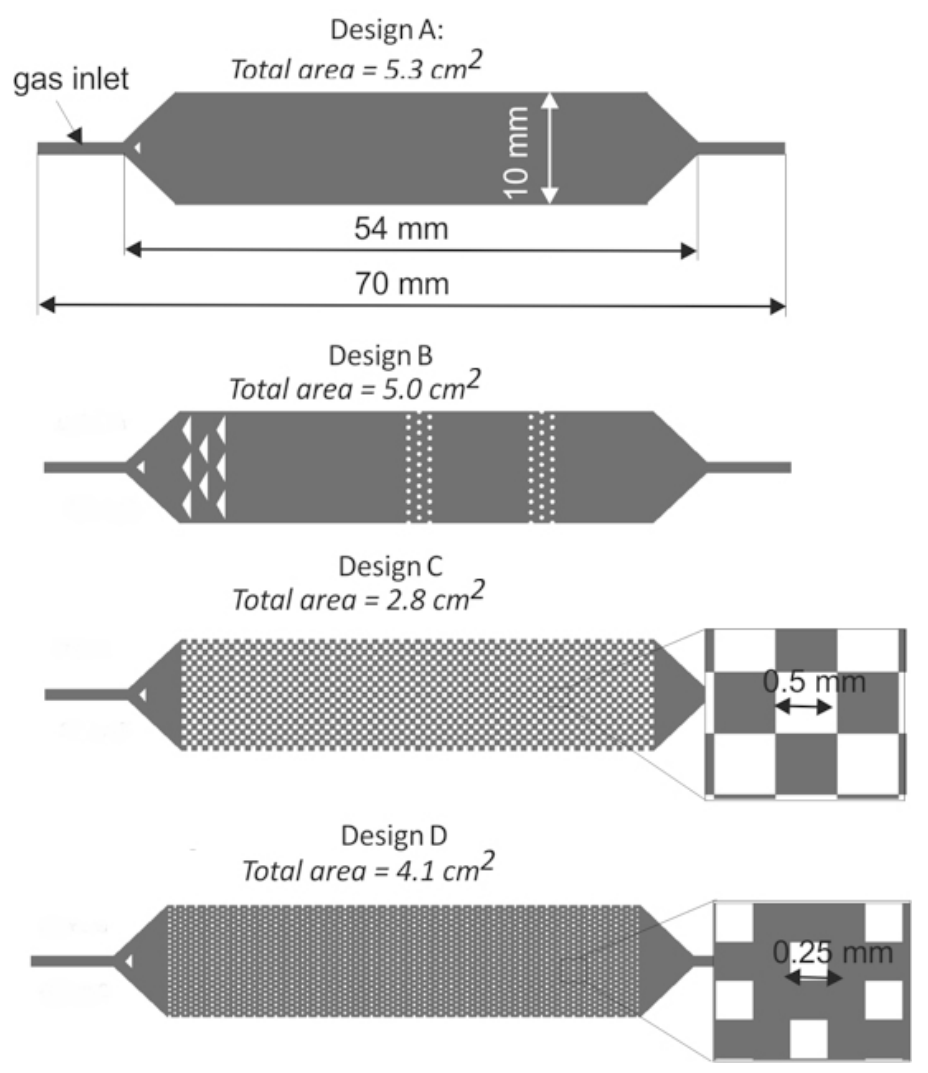

Figure 2. Mask designs for the microconcentrators studied in this work. A: free-space microchannel; B, C and D microchannel with pillars.

Table 1. Main features of the silicate-1 microconcentrators prepared for this work

\begin{tabular}{|c|c|c|c|c|}
\hline Design & $\begin{array}{l}\text { Mask Area } \\
\quad\left(\mathbf{c m}^{2}\right)\end{array}$ & $\begin{array}{l}\text { Exposed Surface } \\
\qquad\left(\mathrm{cm}^{2}\right)\end{array}$ & $\begin{array}{c}\text { Free Volume } \\
(\mu \mathrm{L})\end{array}$ & $\begin{array}{c}\text { Coating Loading } \\
\text { (mg) }\end{array}$ \\
\hline A (free microchannel) & 5.3 & 5.4 & 53.5 & 4.4 \\
\hline B (free microchannel) & 5.0 & 5.2 & 50.1 & 4.1 \\
\hline C (microchannel with pillars) & 2.8 & 5.8 & 45.2 & 4.6 \\
\hline D (microchannel with pillars) & 4.1 & 6.8 & 47.2 & 4.7 \\
\hline
\end{tabular}


Lift-off process (step D) is critical due to zones protected by the ProTEK® PSB resist must be extremely clean to be available for anodic bonding (step E) and to reach a good microdevice sealing. Resist removal is carried out by piranha solution ( $1 \mathrm{H}_{2} \mathrm{O}_{2} 30$ wt.\% : $\left.4 \mathrm{H}_{2} \mathrm{SO}_{4} 95 \%\right)$ (Aldrich) in a ultrasound bath to accomplish zeolite lift-off and resist stripping. Note that higher concentrations of piranha solution are not recommended, due to zeolite layer can also be damaged. After piranha etching, wafer is rinsed and cleaned thoroughly with deionized water under sonication. Before anodic bonding step (step E), the processing wafer is exposed at $480^{\circ} \mathrm{C}$ for $8 \mathrm{~h}$ in an electrical furnace for zeolite activation, i.e. to release the porous framework of the silicalite-1 layer [29-30]. The prefabricated Si wafer is sealed with Borofloat cover (Siegert Wafer $\mathrm{GmbH}$ ) $500 \pm 20 \mu \mathrm{m}$ thick by anodic bonding at $1000 \mathrm{~V}-350^{\circ} \mathrm{C}$.

The final step F is devoted to the resistive Au heater definition on the Si backside. This was carried out by a standard lift-off process with $10 \mathrm{~nm}$ of Cr plus $150 \mathrm{~nm}$ of Au layers deposited by Electron Bean Physical Vapor Deposition (Edwards auto-500), and the photolithography resist TI35ES (Microchemicals) as a sacrificial layer.

Afterwards, the sealed wafers were diced, and the inner and outlet ports, $1 \mathrm{~mm}$ in diameter, were drilled on the Pyrex side by sand blasting process (Alumina dust 170 mesh). Swagelok ${ }^{\circledR}$ stainless steel connections were glued with Loctite Hysol 9492 A\&B (specifically for temperature operation up to $180^{\circ} \mathrm{C}$ ). Figure 3 shows a well-defined silicalite- 1 microconcentrator ready for break-through testing and gas sensing experiments.

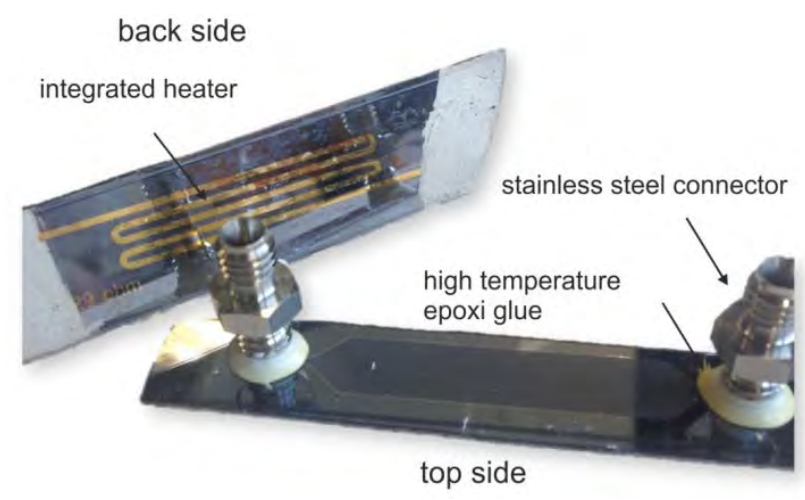

Figure 3. Back side and top view of the silicalite-1 microconcentrator ready for break-through testing.

The heating element was simulated and experimentally tested at different power levels for a proper characterization of the thermal heating by Joule effect with an infrared camera (see Figure 4). In order to avoid material emissivity uncertainties, a black tape (emissivity $\varepsilon=1$ ) was pasted on the microconcentrator backside nearby the Au resistors, and the obtained temperature reading values were used for calibration purposes. The dissipated power levels increase from $14 \mathrm{~mW}$ to $7.76 \mathrm{~W}$ with the DC voltage supply to the resistive element (from 5 to $15 \mathrm{~V}$ ). From the infrared images, the estimated average temperature on the Si backside varies from $36^{\circ}, 83^{\circ} \mathrm{C}, 118^{\circ} \mathrm{C}$ to $160^{\circ} \mathrm{C}$. These experimental values correlate quite well with the predicted by COMSOL Multiphysics. Considering the epoxy glue microfluidic connections, $8 \mathrm{~W}$ will be the maximum power level used for heating during the desorption step. 


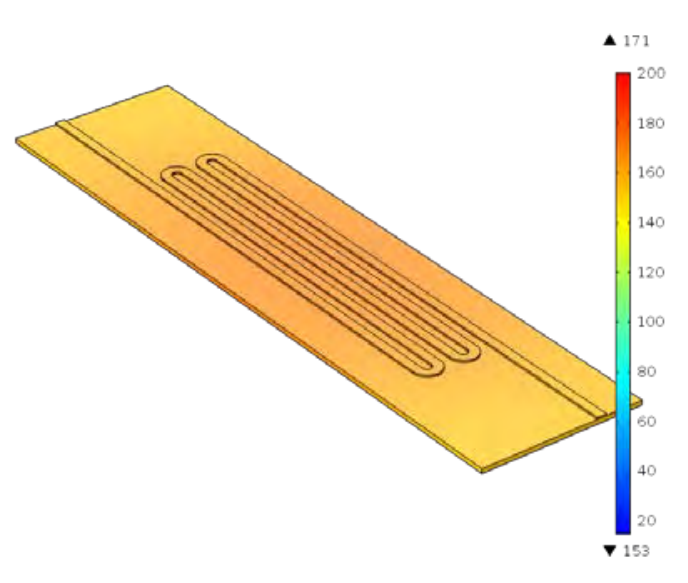

a)
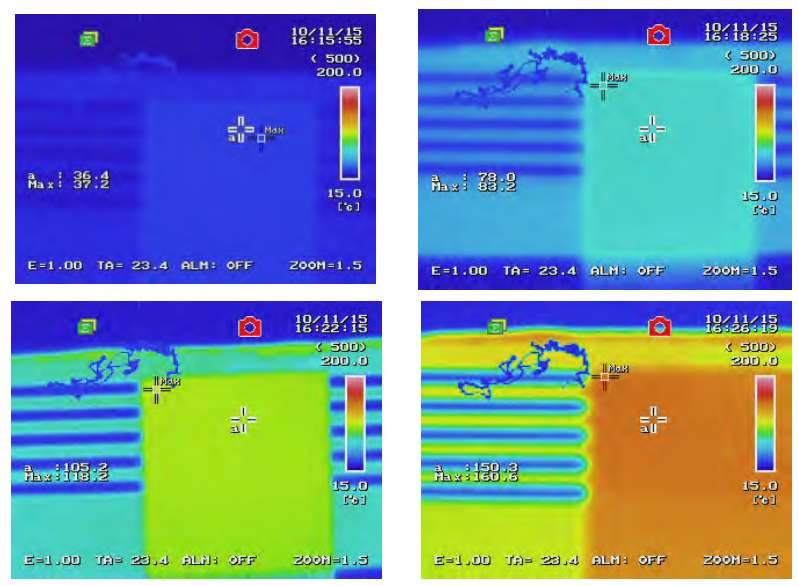

b)

Figure 4. Resistive heater characterization: a) simulation for $15 \mathrm{~V}$; and b) infrared images (from left to right, top to bottom) when $14 \mathrm{~mW}(5 \mathrm{~V}), 3.45 \mathrm{~W}(10 \mathrm{~V}), 4.18 \mathrm{~W}(12 \mathrm{~V})$ and $7.76 \mathrm{~W}(15 \mathrm{~V})$ dissipated power levels.

\section{Experimental details}

\subsection{Experimental set-up}

A synthetic mixture from a certified gas cylinder containing 500 ppmV of $n-\mathrm{C}_{6} \mathrm{H}_{14}$ in dry $\mathrm{N}_{2}$ (Air Products and Chemical. Inc.) was used for all the experimentation. A further dilution with dry $\mathrm{N}_{2}$ (99.999\%) by means of mass-flow controllers was carried out when evaluating the performance of the combined microconcentrator-microcantilever system. The experimental set-up is schematized in Figure 5. For the desorption stage, a DC power (IPS-2303, ISO-TECH) was supplied to the resistive heater. The $\mathrm{n}-\mathrm{C}_{6} \mathrm{H}_{14}$ concentration was continuously monitored either by mass spectrometry (Omnistar, Pfeiffer Vacuum) following the uma=56; or Si based microcantilevers coated with silicalite crystals.

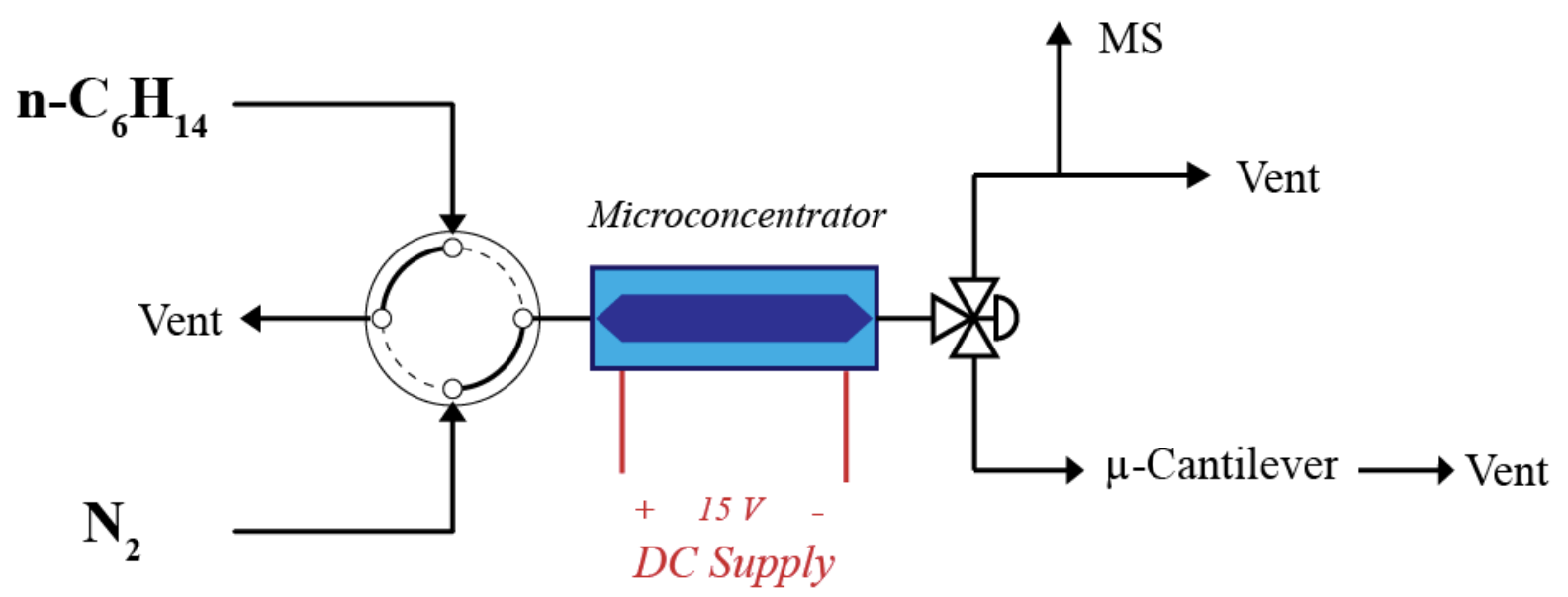

Figure 5. Experimental set-up for breakthrough-testing and sensing.

\subsection{Detection by microcantilevers as chemical sensors}


The micromechanical structures herein used were fabricated from n-type SOI (silicon on insulator) wafers by using standard optical lithography and bulk micromachining technologies with five-levels of masks [41-42]. In general, $\mu$-cantilever sensors are configured to work as tiny microbalances with theoretical mass detection limits around $50 \mathrm{fg}$ for standard fabricated devices. For dynamic mode operation, the effective mass change $(\Delta \mathrm{m})$ due to vapor sorption on the beam could be calculated from the resonance frequency changes $(\Delta \mathrm{f})$. With the final aim of miniaturization and integration, individual heating wires, actuation of the cantilever and mechanical resonance detection are integrated on each cantilever. The actuation is based on the induced Laplace electromagnetic force due to the coupling between the perpendicular magnetic field created by the magnet allocated on the chip basis and the electrical current passing through the coil patterned on the top surface of the $\mu$-cantilever. In order to detect the cantilever oscillation, semiconductor strain gauges are implanted at the surface of the microstructures which are arranged in half Wheatstone bridge configuration. A first gauge is localized where the stresses are maximum (the clamped-end of the beam); and the other reference gauge is on the rigid substrate.

In this work, $\mu$-cantilevers $200 \mu \mathrm{m}$ wide, $15 \mu \mathrm{m}$ thick and from $535 \mu \mathrm{m}$ in length have been used. Thus, the natural resonance frequency and the theoretical mass sensitivity (S) values are $69192 \mathrm{~Hz}$ and $16.7 \mathrm{~Hz} / \mathrm{ng}$, respectively. Similar cantilevers coated with nanoporous materials have been extensively used in our group for VOC and explosive markers detection at ppm level [41-44]. For the purposes of n-hexane detection, the $\mathrm{Si}$ microcantilevers herein used have been coated with silicalite- 1 by evaporative microdropping technique. Silicalite-1 crystals were synthesized in batch under the same protocol as presented in microfabrication section. We spread an ethanolic dispersion of these crystals (4\%wt.) on the top of the surface using piezo-driven inkjet printing technology (MD-E-201H, Microdrop Technologies). For proper control of the sensing material location, we induced instantaneous solvent evaporation during the dispensing process by means of a meander-type heating resistor that is integrated in the cantilever. Following this procedure, the mass deposited, evaluated from the resonant frequency shift, was of $366 \mathrm{ng}$. For the gas sensing type measurements, the chip containing the silicalite-1 coated microcantilever was assembled on a Printed Circuit Board. Afterwards, it was placed in a custom sensor chamber with cross-flow configuration through the cantilever chip to maximize gas-solid contact. This sensor chamber is connected to the micropreconcentrator device by means of SS transfer lines 1/8".

The actuation and detection of the microsensing platform is carried out by a portable low-power electronic interface capable of creating the excitation signal as well as obtaining the response values of resonating microcantilever [44]. This portable electronic interface, also capable to regenerate the nanoporous coating by thermal induced desorption, is solely fed by the $5 \mathrm{~V}$ line from a USB connection to a host computer. The excitation resonance frequency sweeps and dynamic tracking of the mechanical response is performed by means of specific Matlab software implementation

\section{Results and discussion}

\subsection{Silicalite-1 integration on the microfabrication process}

In order to reach a well-sealed zeolitic microfluidic device is very important that zeolite only grows in the microfluidic channels, keeping the top part of silicon wafer completely clean for the anodic bonding. After several compatibility studies about different protecting layers ( $\mathrm{SiN}, \mathrm{SiO}_{2}$, or SU-8) and chemical etchings, we had selected ProTEK ${ }^{\circledR}$ PSB resist as cornerstone of the process, because it is appropriate for $\mathrm{KOH}$ step during channels etching and for silicon protection during silicalite-1 synthesis, and also the lift-off with piranha solution is compatible with synthesized silicalite-1 layer. Due to these three main characteristics of ProTEK ${ }^{\circledR}$ PSB, microfabrication procedure can be carried out directly on the whole wafer and by using standard techniques available in most common microfabrication labs. 
Figure 6 shows SEM images of the microconcentrators at different microfabrication steps. Silicalite- 1 growth was very homogenous along the channel cavity: walls $\left(\varnothing=54.74^{\circ}\right)$ and ground level (Figure 6.c). A preferential orientation (in the crystallographic plane "c") of the well-intergrowth film with a thickness of $4.0 \pm 0.5 \mu \mathrm{m}$ is clearly observed. It should be pointed out that, ProTEK® PSB resist plays as an excellent protector to silicon wafer from alkaline etching during hydrothermal synthesis ( $\mathrm{pH}$ 9-10 during 72 hours at $130^{\circ} \mathrm{C}$ ), because no etching defects (inverted pyramids) are observed in protected area after lift-off process (Figure 6.b). The goodness of the anodic bonding is shown in Figure 6.f where the cross section of the sealed device is depicted. Moreover, in the intersection (Figure 6.b), zeolite is at the same level or under silicon surface level; ensuring a smooth surface for later anodic bonding.

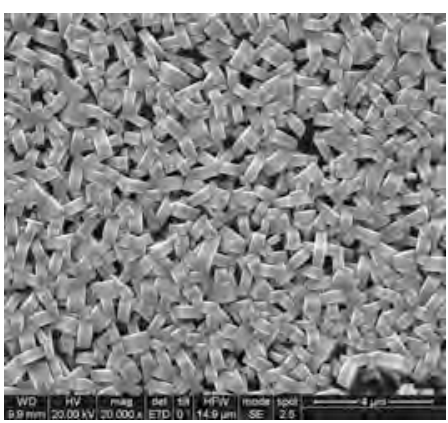

a)

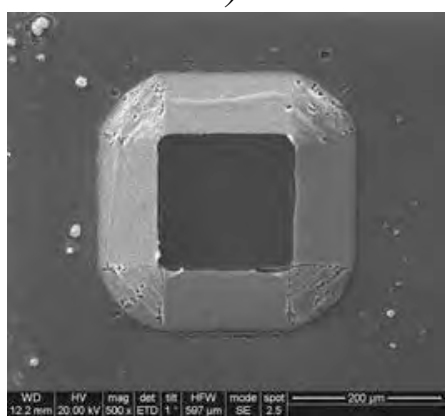

d)

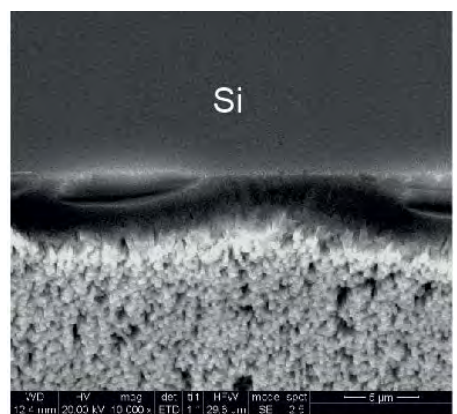

b)

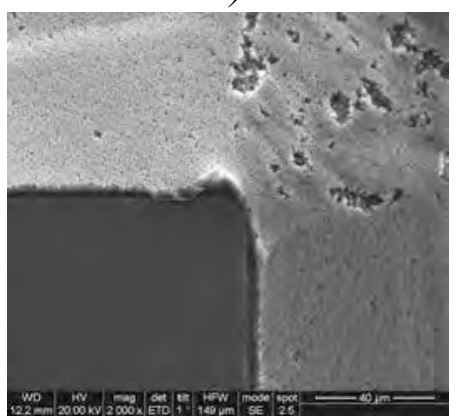

e)

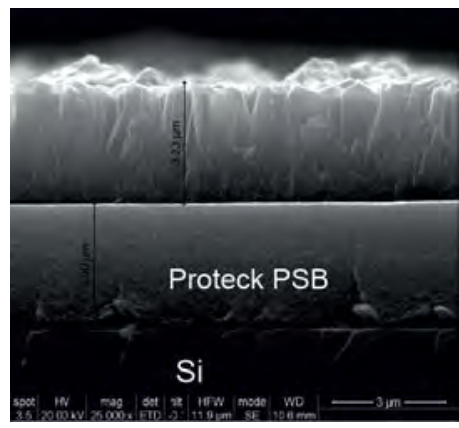

c)

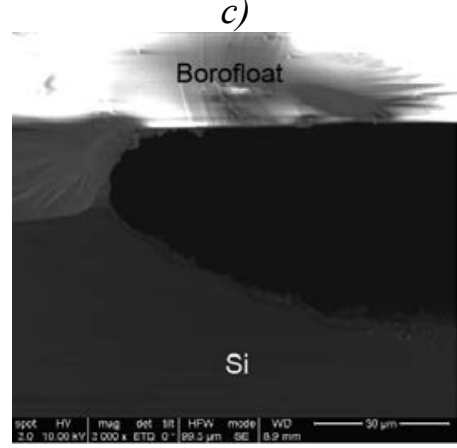

f)

Figure 6. SEM images of silicalite-1 microconcentrators: a) top view of silicalite-1 film grown on the microchannel, b) top view of intersection between silicalite-1 layer and Si after lift-off process, c) cross-section of silicalite-1 layer grown onto Proteck PSB ${ }^{\circledR}$ resist before lift-off process, d) and e) details of pillared structures and f) cross-section of the final sealed device.

\subsection{Standard characterization of the microconcentrators}

In general, the dynamic retention capacity can be determined by continuously drawing a sample of vapor in air through the microconcentrator and monitoring downstream for the appearance of breakthrough. The breakthrough time $t_{0.1}$ is used as the measure of retention capacity and is defined as the time required to observe 0.1 fraction of the inlet vapor concentration downstream from the microconcentrator. Figure 7 shows the typical characterization experiment of one microconcentrator (Design A) by on-line MS. This type of experiment was also conducted with a blank microconcentrator (Design A without zeolite) in order to stablish the delay time of the whole system, being $3.3 \mathrm{~min}$. During the sorption step, a stream of a $5 \mathrm{~mL} / \mathrm{min}$ at room temperature of calibrated hexane is fed to the microconcentrator until breakthrough is observed (Figure 7.b). As it can be observed, the microdevice is designed for exhaustive trapping as the entire mass of vapor(s) from the sample stream has been completely removed along the first $42 \mathrm{~min}$. From the first portion of the breakthrough curve, i.e. up to $\mathrm{C} / \mathrm{C}_{0}=0.05$ where the sorption active centers are in clear excess, mass 
transfer kinetic coefficient of $6184 \mathrm{~min}^{-1}$ has been calculated following the procedure detailed elsewhere [18].

The saturation point, $\mathrm{t}_{0.95}$, is defined as the time required to observe 0.95 fraction of the inlet vapor concentration downstream. At this moment, discharge phase starts and the flow injected to the microconcentrator is switched to dry nitrogen ( $2 \mathrm{~mL} / \mathrm{min})$, and DC voltage is applied to the resistive heater printed on the backside of the microconcentrator.

The most significant figure of merit for a preconcentrator is the preconcentration factor (PCF), which is the ratio of the concentration of the analyte in the sample delivered to the detector "C" $\mathrm{C}$ "to the concentration originally present in the inlet flow " $\mathrm{C}_{0}$ ". A direct value of preconcentrator factor (PFC) for design A can be extracted directly from the Figure 7.a. With the proposed silicalite-1 microconcentrator PFC of $48.9 \pm 10.4$ (average from 4 experiments at identical conditions) has been attained. The PCF of blank microconcentrator is 1 in agreement with a negligible contribution of $n$ hexane on bulk silicon.

Furthermore, we have estimated the efficiency of the microconcentrator design by using (1), where $q_{b}$ represents useful capacity of the bed [49] and $q_{s}$ is the total capacity of the bed. These values can also be calculated as from the areas marked in Figure 7.b: $\mathrm{A}$ at $\mathrm{t}_{0.10}$ and $\mathrm{B}$ at $\mathrm{t}_{0.95}$.

$$
\text { sorption efficiency }=\frac{q_{b}}{q_{s}}=\frac{A}{(A+B)}
$$

Accordingly, the A type preconcentrator exhibits an efficiency of $0.918 \pm 0.010$. This value underlines the goodness of vapor-solid contact on the zeolite washcoated microfluidic channel with tangential flow.

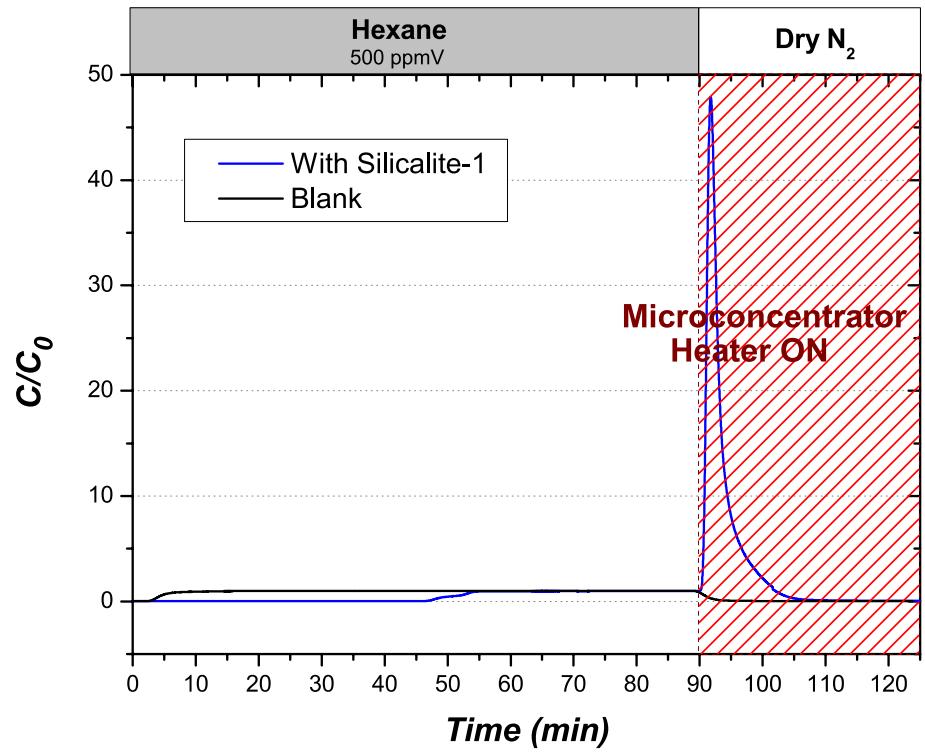

a) 


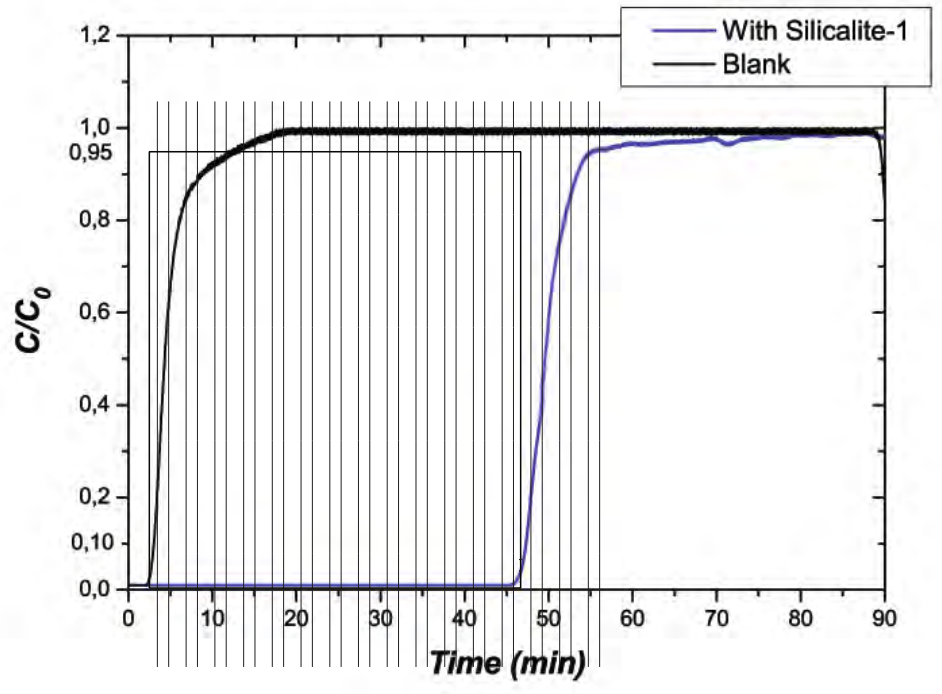

b)

Figure 7. a) Adsorption-Desorption experiment of A type microconcentrator under standard conditions followed by MS; b) Comparison of the Break-through curve for type A design without (blank) and with silicalite-1 layer.

Following this procedure, the microconcentrators described in Table 1 have been fully characterized under standard conditions. Table 2 summarizes the main results achieved. In order to make a comparison between micro and macro devices, experiments carried out with a macropreconcentrator wrapped with wire heaters (fix-bed with similar zeolite loading: $4.8 \mathrm{mg}$ of silicalite-1 diluted with quartz to avoid bypass and preferential channels) are also shown. The main conclusion is that all microconcentrators have higher efficiency than fix-bed due to the uniform zeolite distribution along the contactor and the improved gas-solid contact. In addition, at the same temperature, microconcentrators achieve better PCF than fix-bed because of the integrated heater and the higher heat transfer rates. In general, are characterized by large dead volumes and limited heating efficiency due to their larger thermal mass, which subsequently contributes to the delivery of a broad time width pulse of vapor [9-10]. The comparison between the four microconcentrator designs does not show significant differences, as the adsorption efficiency exceeds $90 \%$ for all of them. These results reveal that the zeolite integration during the microfabrication process has been successfully accomplished, not been necessary the patterning of fluid distributors or pillared features to improve gas-solid contact. Thus, the integration on process has proved to be feasible for the incorporation of inorganic microporous coatings on microdevices, avoiding cumbersome and inefficient post-fabrication procedures. 
Table 2. Summary of the basic characterization results for the silicalite-1 microconcentrators under standard conditions.

\begin{tabular}{|c|c|c|c|}
\hline Preconcentrator & Type & $\begin{array}{c}\text { Adsorption* } \\
\text { Efficiency }\end{array}$ & $\begin{array}{c}\text { PCF* } \\
\text { (desorption Temperature })\end{array}$ \\
\hline Design A & free microchannel & $0.918 \pm 0.010$ & $48.9 \pm 10.4\left(150^{\circ} \mathrm{C}\right)$ \\
\hline Design B & free microchannel & $0.903 \pm 0.023$ & $42.6 \pm 15.3\left(150^{\circ} \mathrm{C}\right)$ \\
\hline Design C & $\begin{array}{c}\text { microchannels with } \\
\text { pillars }\end{array}$ & $0.888 \pm 0.011$ & $13.7 \pm 2.5\left(105^{\circ} \mathrm{C}\right)$ \\
\hline Design D & $\begin{array}{c}\text { microchannels with } \\
\text { pillars }\end{array}$ & $0.946 \pm 0.010$ & $30.9 \pm 1.2\left(150^{\circ} \mathrm{C}\right)$ \\
\hline Macro & Fix-bed & $0.471 \pm 0.046$ & $28.5\left(150^{\circ} \mathrm{C}\right)$ \\
\hline
\end{tabular}

*average of 4 different tests under identical conditions

The desorption bandwidth play a key role on the preconcentrator performance. Desirable features include, among others, thermal heating with short time constants to reduce power consumption. Figure 8 shows the importance of desorption temperature on the PCF values. The microdevices were thermostated for all tests by applying pulse width modulation to 10-12-15-20 V bias to the on-chip heaters during the whole desorption stage, i.e above $5 \mathrm{~min}$ in duration. Thus, desorption experiments with A type design were conducted at temperatures varying from $105^{\circ} \mathrm{C}$ to $170^{\circ} \mathrm{C}$. Average results for a given desorption temperature are compiled in Table 3.

As it was expected, the PCF values increases with temperature from $12.4 \pm 2.5$ at $105^{\circ} \mathrm{C}$ to $58.3 \pm$ 3.0 at $170^{\circ} \mathrm{C}$ due to the endothermic character of the desorption process. Correspondingly, the desorption bandwidth decreases with temperature from $233 \mathrm{~s}$ at $105^{\circ} \mathrm{C}$ to $107 \mathrm{~s}$ at $170^{\circ} \mathrm{C}$. These values are clearly exceeding those commonly reported in the literature, within the order of few seconds [1619] for VOCs on commercial carbon. Our explanation relies on the desorption temperature values herein used, somewhat hindered by the microfluidic connections capable to withstand maximum temperature of $180^{\circ} \mathrm{C}$. In fact, these values are clearly lower than those commonly reported in the literature for hexane desorption on MFI type zeolites around $300^{\circ} \mathrm{C}$ [38]; or even those used on microconcentrators coated with activated carbons, around $225^{\circ} \mathrm{C}$ [16-19]. It could be concluded that the operational performance could be notably improved by using high-temperature microfluidic connections.

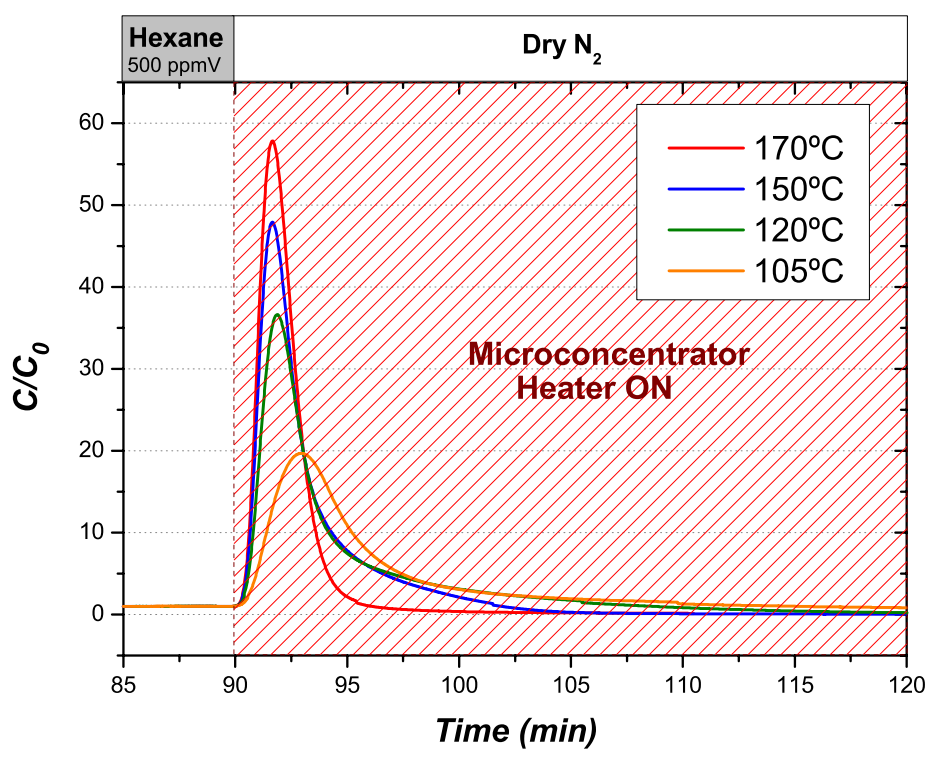

Figure 8. Influence of desorption temperature on PCF values for type A microconcentrators. 
Table 3. Average* PCF for type A microconcentrators as a function of desorption temperature.

\begin{tabular}{|c|c|c|c|c|}
\hline Temperature $\left({ }^{\circ} \mathbf{C}\right)$ & 105 & 120 & 150 & 170 \\
\hline PFC & $12.4 \pm 2.5$ & $38.6 \pm 3.1$ & $48.9 \pm 10.4$ & $58.3 \pm 3.0$ \\
\hline
\end{tabular}

* of 3 different tests under identical conditions

\subsection{Assessment on the preconcentration performance}

As it was already mentioned in section above, the basic characterization of microconcentrators has been carried out under standard conditions, i.e $5 \mathrm{~mL} / \mathrm{min}$ (adsorption flow rate), $2 \mathrm{~mL} / \mathrm{min}$ (desorption flow rate) and $150^{\circ} \mathrm{C}$ as desorption temperature. However, another desirable feature of preconcentrator device include operation at high flow rates. In this work, we have attempted to evaluate the dynamic retention capabilities of the fabricated devices. Thus, the performance of the type A microconcentrator has been assessed by the modified Wheeler Model [18-19]. This model relates several important design and operating parameters and involves both thermodynamic and kinetic factors. Among others, the critical bed residence time, $\tau_{\text {critical }}$, represents the practical limit to miniaturization. That is, for a given value of $\mathrm{Q}$, this defines the minimum volume of the microdevice; or for a given size, this determines the critical maximum flow rate, $\mathrm{Q}_{\text {critical }}$. Based on our experimentally evaluated equilibrium and kinetic data, the critical values are compiled in Table 4. The minimum concentrator volume is $2.43 \mu \mathrm{L}$ for the standard flow rate, i.e. $4.5 \%$ of the free volume for type A design (see Table 1). Similarly, the standard flow rate is $4.5 \%$ of the estimated critical value of $109 \mathrm{~mL} / \mathrm{min}$; indicating that it could be enlarged further to reduce sampling time.

With a goal of developing a general guideline for stipulating maximum operating flow rates of $\mu$ preconcentrators; a cut-off value at $60 \%$ bed efficiency is generally adopted [18-19]. The value of bed residence time associated with this efficiency cut-off is considered the minimum safe value, $\tau_{\text {safe }}$, and the corresponding safe (i.e., maximum recommended) flow rate is therefore designated $\mathrm{Q}_{\text {safe. }}$. The as calculated values are $72 \mathrm{~ms}$ and $44 \mathrm{~mL} / \mathrm{min}$ for $\tau_{\text {safe }}$ and $\mathrm{Q}_{\text {safe }}$, respectively. It could be concluded that the operational performance of the as prepared microconcentrators is amenable for further improvement by increasing the flow rate values.

Table 4. Critical and "safe" values of $\tau$ and Q compared to standard conditions used in this work.

\begin{tabular}{|c|c|c|c|c|c|}
\hline$\tau_{\text {exptal }}$ & $\mathbf{Q}_{\text {exptal }}$ & $\boldsymbol{\tau}_{\text {critical }}$ & $\mathbf{Q}_{\text {critical }}$ & $\boldsymbol{\tau}_{\text {safe }}$ & $\mathbf{Q}_{\text {safe }}$ \\
\hline $636 \mathrm{~ms}$ & $5 \mathrm{~mL} / \mathrm{min}$ & $29 \mathrm{~ms}$ & $109 \mathrm{~mL} / \mathrm{min}$ & $72 \mathrm{~ms}$ & $44 \mathrm{~mL} / \mathrm{min}$ \\
\hline
\end{tabular}

\subsection{Performance of the combined microconcentrator-microcantilever system for $n$-hexane detection}

In general, the microconcentrator is capable for substantially improvement on detector sensitivity and selectivity. We have coupled the microdevice to a microcantilever chip for n-hexane detection as "proof of concept" demonstration.

For such purposes, we have previously calibrated the response of silicalite-1 coated microcantilever upon exposure to different n-hexane concentrations at ppm level (see Figure 9). The cantilever calibration is carried out from known n- $\mathrm{C}_{6} \mathrm{H}_{14}-\mathrm{N}_{2}$ mixtures and following the standard procedures already described in our previous works [41-44]. In particular, concentration steps 10 min in duration were performed sequentially, i.e., $100 \mathrm{ppmV}$ then $200 \mathrm{ppmV}$ and so on until reach a final concentration of $500 \mathrm{ppmV}$. Afterwards, a similar decreasing concentration pattern is applied. Figure 9 
shows the resulting frequency shift for each concentration step. From the registered values, the calculated sensor sensitivity is $0.2981 \mathrm{~Hz} / \mathrm{ppmV}$. Accounting from the experimental signal noise (about $1 \mathrm{~Hz}$ ), theoretical limit of detection (LOD) value below $10 \mathrm{ppmV}$ is obtained.As it can be observed in Figure 9, the recovery of the baseline using dry $\mathrm{N}_{2}$ as sweep gas at room temperature is incomplete, indicating that hexane remains adsorbed due to the high affinity of the silicalite- 1 towards hexane. To this end, the "in situ" zeolite degassing is performed by applying an adequate dc voltage to the heating resistor embedded on the cantilever tip [41-44].

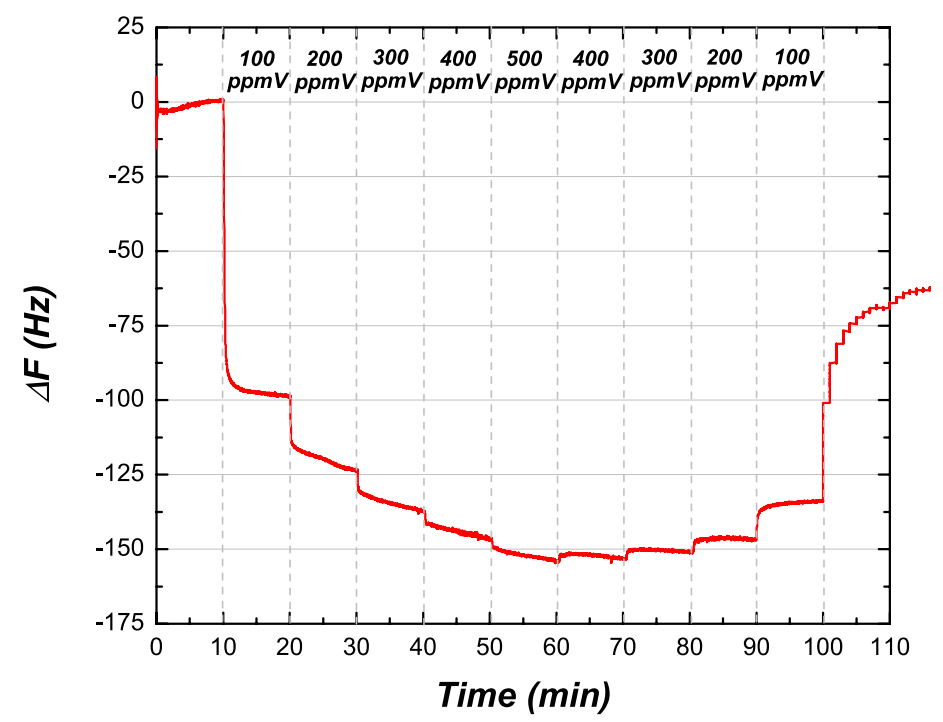

Figure 9. Evolution of the resonant frequency upon the introduction of n-hexane vapors at room temperature for the $\mathrm{Si}$ microcantilever coated with silicalite-1 crystals.

Once microcantilever calibration is accomplished and the sensing material is fully regenerated, the microconcentrator unit is connected upstream of the microcantilever sensor and the whole system "microconcentrator plus microcantilever" is ready to operate. Figure 10 shows a standard sensing experiment of A type microconcentrator by on-line Si microcantilever coated with silicalite- 1 crystals. Firstly, the resonant frequency baseline is established by sweeping dry nitrogen $(10 \mathrm{~mL} / \mathrm{min})$ for 5 minutes. Afterwards, the sorption stage is performed at $100 \mathrm{ppmV}-10 \mathrm{~mL} / \mathrm{min}$ for 5 minutes. During this period, the frequency shift registered, once stabilized, is circa $20 \mathrm{~Hz}$, i.e. lower than the sensor response depicted in Figure 9 for similar concentration $(\sim 100 \mathrm{~Hz})$. This behaviour is indicating a huge part of the hexane in the nitrogen stream is being adsorbed on the A type microconcentrator. For the desorption stage, $10 \mathrm{~mL} / \mathrm{min}$ of dry $\mathrm{N}_{2}$ are fed to the microdevice. This injection, some delayed due to volume of transfer lines, modifies the sensor response; although the effect is clearly noticeable when the microconcentrator heater is activated for $2.5 \mathrm{~min}$. A huge desorption peak is registered with a maximum frequency shift above $150 \mathrm{~Hz}$. This instantaneous frequency shift agrees with the cantilever signal when directly exposed to $\sim 500 \mathrm{ppmV}$. Thanks to the A type microconcentrator, the whole system "microconcentrator plus microcantilever" improves in 5 fold the n-hexane detection capabilities. Once the DC power is switched off, n-hexane desorption on the microconcentrator by the sweep gas takes place at lower rate. Finally, silicalite -1 from both, the microconcentrator and the microcantilever, is fully regenerated by Joule-effect heating. 


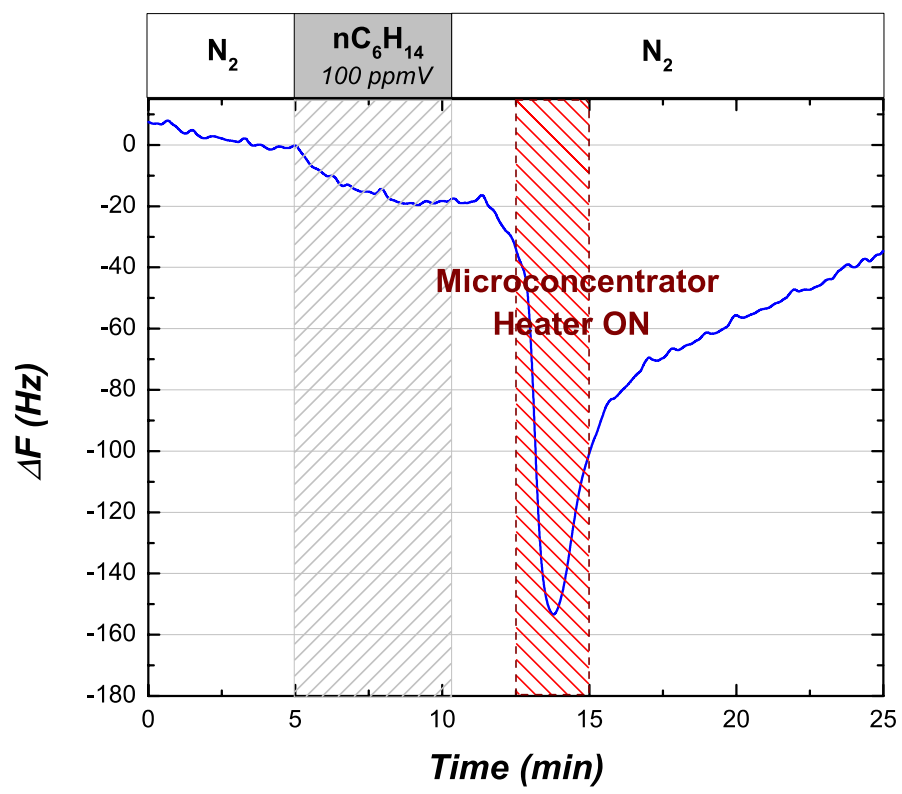

Figure 10. Adsorption-Desorption experiment of $100 \mathrm{ppmV}$ of n-hexane over A type microconcentrator followed by the Si microcantilever coated with silicalite-1 crystals.

\section{Conclusions}

MEMS microconcentrators with integrated silicalite-1 polycrystalline layers as stationary phase have been successfully prepared by following a 6-step microfabrication process. The n-hexane breakthrough curves at standard conditions reveal that the zeolite integration during the microfabrication process has been successfully accomplished, not been necessary the patterning of fluid distributors or pillared features to improve gas-solid contact. Thus, the incorporation of inorganic microporous coatings on the integrated process has proved to be feasible, avoiding cumbersome and inefficient post-fabrication procedures.

The silicalite-1 microconcentrators outperform the conventional macro preconcentrator due to the uniform and homogeneous zeolite distribution along the microfluidic channel, the improved gas-solid contact on the washcoated device and the superior heating efficiency. Among the tested, type A microconcentrators are clearly outstanding with PCF of $58.3 \pm 3.0$ at $170^{\circ} \mathrm{C}$ as desorption temperature and desorption bandwidth of 107s. Taking into account the n-hexane - silicalite-1 interactions, the PCF of the as prepared microdevices could be notably improved by using high-temperature microfluidic connections in order to increase the desorption temperature values. In addition, the analysis of the dynamic retention capabilities of the microconcentrators indicates that the operational performance (sampling time and retention capacity) is amenable for further improvement by increasing the flow rate values from $5 \mathrm{~mL} / \mathrm{min}$ to $42 \mathrm{~mL} / \mathrm{min}$. The goodness of the combined microconcentrator microcantilever system has been validated for detection of $100 \mathrm{ppmV}$ of n-hexane, with a 5 fold increase in the sensitivity of the whole system.

\section{Acknowledgements}

Financial support from financial support from MICINN (CTQ2013-49068-C2-1-R; CTQ2013-49068C2-2-R) and Gobierno de Aragon is gratefully acknowledged.

\section{References}


1. Bhagat, A.A.S., Bow, H., Hou, H.W., Tan, S.J., Han, J., and Lim, C.T., "Microfluidics for cell separation". Medical \& Biological Engineering \& Computing, 2010. 48(10): p. 999-1014.

2. $\quad$ Dittrich, P.S. and Manz, A., "Lab-on-a-chip: microfluidics in drug discovery". Nature Reviews Drug Discovery, 2006. 5(3): p. 210-218.

3. Neuzil, P., Giselbrecht, S., Lange, K., Huang, T.J., and Manz, A., "Revisiting lab-on-a-chip technology for drug discovery". Nature Reviews Drug Discovery, 2012. 11(8): p. 620-632.

4. Sato, K., Hibara, A., Tokeshi, M., Hisamoto, H., and Kitamori, T., "Microchip-based chemical and biochemical analysis systems". Advanced Drug Delivery Reviews, 2003. 55(3): p. 379391.

5. Wang, J., "From DNA biosensors to gene chips". Nucleic Acids Research, 2000. 28(16): p. 3011-3016.

6. Brivio, M., Verboom, W., and Reinhoudt, D.N., "Miniaturized continuous flow reaction vessels: influence on chemical reactions". Lab on a Chip, 2006. 6(3): p. 329-344.

7. Mark, D., Haeberle, S., Roth, G., von Stetten, F., and Zengerle, R., "Microfluidic lab-on-achip platforms: requirements, characteristics and applications". Chemical Society Reviews, 2010. 39(3): p. 1153-1182.

8. Vereshchagina, E., Wolters, R.A.M., and Gardeniers, J.G.E., "The development of titanium silicide-boron-doped polysilicon resistive temperature sensors". Journal of Micromechanics and Microengineering, 2011. 21(10): p. 105022.

9. Voiculescu, I., Zaghloul, M., and Narasimhan, N., "Microfabricated chemical preconcentrators for gas-phase microanalytical detection systems". Trends in Analytical Chemistry, 2008. 27(4): p. 327-343

10. Lahlou, H., Vilanova, X., and Correig, X., "Gas phase micro-preconcentrators for benzene monitoring: A review". Sensors and Actuators B: Chemical, 2013. 176: p. 198-210

11. Lambertus, G., Elstro, A., Sensenig, K., Potkay, J., Agah, M., Scheuering, S., Wise, K., Dorman, F., and Sacks, R., "Design, Fabrication, and Evaluation of Microfabricated Columns for Gas Chromatography". Analytical Chemistry, 2004. 76(9): p. 2629-2637.

12. Lu, C.-J., Steinecker, W.H., Tian, W.-C., Oborny, M.C., Nichols, J.M., Agah, M., Potkay, J.A., Chan, H.K.L., Driscoll, J., Sacks, R.D., Wise, K.D., Pang, S.W., and Zellers, E.T., "First-generation hybrid MEMS gas chromatograph". Lab on a Chip, 2005. 5(10): p. 11231131.

13. Agah, M., Lambertus, G.R., Sacks, R., and Wise, K., "High-Speed MEMS-Based Gas Chromatography". Journal of Microelectromechanical Systems, 2006. 15(5): p. 1371-1378.

14. Alfeeli, B., and Agah, M., "MEMS-based selective preconcentration of trace level breath analytes semi-packed gas chromatography columns". IEEE Sensors Journal, 2009. 9(9): p. 1068-1075.

15. Narayanan, S., Alfeeli, B., and Agah, M., "Two-Port Static Coated Micro Gas Chromatography Column With an Embedded Thermal Conductivity Detector". Sensors Journal, IEEE, 2012. 12(6): p. 1893-1900

16. Kim, S.-J., Serrano, G., Wise, K.D., Kurabayashi, K., and Zellers, E.T., "Evaluation of a Microfabricated Thermal Modulator for Comprehensive Two-Dimensional Microscale Gas Chromatography". Analytical Chemistry, 2011. 83(14): p. 5556-5562.

17. Kim, S.-J., Chang, H., and Zellers, E.T., "Microfabricated Gas Chromatograph for the Selective Determination of Trichloroethylene Vapor at Sub-Parts-Per-Billion Concentrations in Complex Mixtures". Analytical Chemistry, 2011. 83(14): p. 7198-7206.

18. Sukaew, T., Zellers, E.T., " Evaluating the dynamic retention capacities of microfabricated vapor preconcentrators as a function of flow rate". Sensors and Actuators B: Chemical, 2013. 183: p. 163-171.

19. Bryant-Genevier, J. and Zellers, E.T., "Toward a microfabricated preconcentrator-focuser for a wearable micro-scale gas chromatograph". Journal of Chromatography A, 2015. 1422: p. 299-309. 
20. Mohsen, Y., Sanchez, J.-B., Berger, F., Lahlou, H., Bezverkhyy, I., Fierro, V., Weber, G., Celzard, A., and Bellat, J.-P., "Selection and characterization of adsorbents for the analysis of an explosive-related molecule traces in the air". Sensors and Actuators B: Chemical, 2013. 176(0): p. 124-131.

21. Sanchez, J.B., Schmitt, A., Berger, F., and Mavon, C., "Silicon-Micromachined Gas Chromatographic Columns for the Development of Portable Detection Device". Journal of Sensors, 2010.

22. Alfeeli, B., Jain, V., Johnson, R.K., Beyer, F.L., Heflin, J.R., and Agah, M., "Characterization of poly(2,6-diphenyl-p-phenylene oxide) films as adsorbent for microfabricated preconcentrators". Microchemical Journal, 2011. 98(2): p. 240-245.

23. Alfeeli, B., Taylor, L.T., and Agah, M., "Evaluation of Tenax TA thin films as adsorbent material for micro preconcentration applications". Microchemical Journal, 2010. 95(2): p. 259-267.

24. Gràcia, I., Ivanov, P., Blanco, F., Sabaté, N., Vilanova, X., Correig, X., Fonseca, L., Figueras, E., Santander, J., and Cané, C., "Sub-ppm gas sensor detection via spiral $\mu$-preconcentrator". Sensors and Actuators B: Chemical, 2008. 132(1): p. 149-154.

25. Camara, E.H.M., Breuil, P., Briand, D., Guillot, L., Pijolat, C., and de Rooij, N.F., "Micro gas preconcentrator in porous silicon filled with a carbon absorbent". Sensors and Actuators B: Chemical, 2010. 148(2): p. 610-619.

26. Coronas, J. and Santamaria, J., "The use of zeolite films in small-scale and micro-scale applications". Chemical Engineering Science, 2004. 59(22-23): p. 4879-4885.

27. Pina, M.P., Mallada, R., Arruebo, M., Urbiztondo, M., Navascues, N., de la Iglesia, O., and Santamaria, J., "Zeolite films and membranes. Emerging applications". Microporous and Mesoporous Materials, 2011. 144(1-3): p. 19-27.

28. Pellejero, I., Urbiztondo, M., Villarroya, M., Sese, J., Pina, M.P., and Santamaria, J., "Development of etching processes for the micropatterning of silicalite films". Microporous and Mesoporous Materials, 2008. 114(1-3): p. 110-120

29. Pellejero, I., Agusti, J., Urbiztondo, M.A., Sese, J., Pina, M.P., Santamaria, J., and Abadal, G., "Nanoporous silicalite-only cantilevers as micromechanical sensors: Fabrication, resonance response and VOCs sensing performance". Sensors and Actuators B-Chemical, 2012. 168: p. 74-82.

30. Pellejero, I., Urbiztondo, M.A., Pina, M.P., and Santamaria, J., "Reinforced SW-1 micromembranes integrated on chip: Application to $\mathrm{CO}_{2}$ separation". Journal of Membrane Science, 2014. 460: p. 34-45.

31. Serrano, G., Reidy, S.M., and Zellers, E.T., "Assessing the reliability of wall-coated microfabricated gas chromatographic separation columns". Sensors and Actuators B: Chemical, 2009. 141(1): p. 217-226.

32. Wong, M-Y., Cheng, W-R., Liu, M-H., Tian, W-C., Lu, C-J., "A preconcentrator chip employing $\mu$-SPME array coated with in-situ-synthesized carbon adsorbent film for VOCs analysis". Talanta, 2012. 101: p307-313.

33. Chae, M.-S., Kim, J., Yoo, Y., Kang, J., Lee, J., and Hwang, K., "A Micro-Preconcentrator Combined Olfactory Sensing System with a Micromechanical Cantilever Sensor for Detecting 2,4-Dinitrotoluene Gas Vapor". Sensors, 2015. 15(8): p. 18167.

34. Shakeel, A., Wang, D., Randy Heflin, R., and Agah, M., "Width-modulated microgas chromatography separation columns with silica nanoparticles stationary phase". IEEE SENSORS 2013 - Proceedings 6688124l, 2008. 133(1): p. 24-32.

35. Alfeeli, B., Cho, D., Ashraf-Khorassani, M., Taylor, L.T., and Agah, M., "MEMS-based multiinlet/outlet preconcentrator coated by inkjet printing of polymer adsorbents". Sensors and Actuators B: Chemical, 2008. 133(1): p. 24-32 
36. Martin, M., Crain, M., Walsh, K., McGill, R.A., Houser, E., Stepnowski, J., Stepnowski, S., $\mathrm{Wu}, \mathrm{H} .-\mathrm{D}$. , and Ross, S., "Microfabricated vapor preconcentrator for portable ion mobility spectroscopy". Sensors and Actuators B: Chemical, 2007. 126(2): p. 447-454.

37. Cosseron, A-F., Daou, T.J., Tzanis, L., Nouali, H., Deroche, I., Coasne, B., Tchamber, V., "Adsorption of volatile organic compounds in pure silica CHA, /BEA, MFI and STT-type zeolites". Microporous and Mesoporous Materials, 2013. 173: p. 147-154.

38. Ferreira, A.F.P., Marjo, Mittelmeijer-Hazeleger, M.C., Bergh, J., Aguado, S., Jansen, J.C., Rothenberg, G., Rodrigues, A.E., and Kapteijn, F., "Adsorption of hexane isomers on MFI type zeolites at ambient temperature:Understanding the aluminium content effect". Microporous and Mesoporous Materials, 2013. 170: p. 26-35.

39. Sun, X., Li, Y., Xi, H., and Xiaerreira, Q., "Adsorption performance of a MIL101(Cr)/graphite oxide composite for a series of n-alkanes". RSC Advances, 2014. 4: p. 56216-56223.

40. Vázquez, R., Lakhmi, R., Debéda, H., Arregui, F.J., Zamarreño, C.R., Delgado, M., Lucat, C., and Llobet, E., "Functionalized screen-printed PZT cantilevers for room temperature benzene detection". Procedia Engineering, 2011. 25: p. 1077-1080.

41. Urbiztondo, M.A., Peralta, A., Pellejero, I., Sese, J., Pina, M.P., Dufour, I., and Santamaria, J., "Detection of organic vapours with Si cantilevers coated with inorganic (zeolites) or organic (polymer) layers". Sensors and Actuators B: Chemical, 2012. 171-172: p. 822-831.

42. Urbiztondo, M.A., Pellejero, I., Villarroya, M., Sese, J., Pina, M.P., Dufour, I., and Santamaria, J., "Zeolite-modified cantilevers for the sensing of nitrotoluene vapors". Sensors and Actuators B: Chemical, 2009. 137: p. 608-616.

43. Pina, M.P., Almazán, F., Eguizábal, A., Pellejero, I., Urbiztondo, M., Sesé, J., Santamaría, J., García-Romeo, D., Calvo, B., and Medrano, N. "Explosives detection by array of Si $\mu-$ cantilevers coated with titanosilicate type nanoporous materials". in Proceedings of IEEE Sensors. 2014, 6985276, p: 1407-1410.

44. Garcia-Romeo, D., Pellejero, I., Urbiztondo, M.A., Sese, J., Pina, M.P., Martinez, P.A., Calvo, B., and Medrano, N., "Portable low-power electronic interface for explosive detection using microcantilevers". Sensors and Actuators B-Chemical, 2014. 200: p. 31-38.

45. Dragonieri, S., Annema, J.T., Schot, R., van der Schee, M.P.C., Spanevello, A., Carratú, P., Resta, O., Rabe, K.F., and Sterk, P.J., "An electronic nose in the discrimination of patients with non-small cell lung cancer and COPD". Lung Cancer, 2009. 64(2): p. 166-170.

46. Righettoni, M., Tricoli, A., and Pratsinis, S.E., " $\mathrm{WO}_{3}$ Sensors for Highly Selective Detection of Acetone for Easy Diagnosis of Diabetes by Breath Analysis". Analytical Chemistry, 2010. 82(9): p. 3581-3587.

47. Rosier, E., Loix, S., Develter, W., Van de Voorde, W., Tytgat, J., and Cuypers, E., "The Search for a Volatile Human Specific Marker in the Decomposition Process". PLoS ONE, 2015. 10(9): p. e0137341.

48. Rahim, R., Bais, B., Majlis, B., and Sugandi, G., "ProTEK PSB coating as an alternative polymeric protection mask for $\mathrm{KOH}$ bulk etching of silicon". Microsystem Technologies, 2013. 19(6): p. 905-914.

49. Seader, J.D., and Henley, E.J. "Adsorption, Ion Exchange and Chromatography". Separation Process Principles. Ed. John Wiley \& Sons; Hoboken, NJ, $2^{\text {nd }}$ Ed. 2006. 